\title{
Study of the Relationship between Parenting Attitude of Youth Fostering and Creativity among Students of Universities
}

\author{
Bahareh Azizi Nejad ${ }^{1}$, Hossein Jenaabadi' ${ }^{2}$, Nazila Ghafarshuja ${ }^{3}$, Hagigat Heydaribisafar ${ }^{4}$ \\ ${ }^{1}$ Department of Human Science, Payame Noor University, Tehran, Iran \\ ${ }^{2}$ Department of Education, University of Sistan and Baluchestan, Zahedan, Iran \\ ${ }^{3}$ Islamic Azad University, Saveh Branch, Saveh, Iran \\ ${ }^{4}$ Islamic Azad University, Urmia Branch, Urmia, Iran \\ Email: Bahareh19@gmail.com
}

Received 17 December 2014; accepted 1 February 2015; published 9 April 2015

Copyright (C) 2015 by authors and Scientific Research Publishing Inc.

This work is licensed under the Creative Commons Attribution International License (CC BY). http://creativecommons.org/licenses/by/4.0/

(c) (i) Open Access

\begin{abstract}
Nowadays, creativity is the main need for continuing the life in the various aspects of society, especially education. Parenting attitude of youth fostering as an important factor can be effect on creativity, because youth are dependent to parents and they are as power recourse for youth. Youth are in interaction with parents and parents can be ready appropriate filed in home and family to efflorescence their youth's creativity. The present study undertakes to provide a descriptive and correlative analysis on the relationship between youth fostering and student creativity. Parenting attitudes (including domination, high dependency, and negligence) and creativity (including fluency, originality, flexibility and elaboration) are taken as independent and dependent variables, respectively. To test the hypotheses, information collected from three questionnaires was analyzed: 1) multiple choice paper and pencil test for measuring Torrance creativity (1973), 2) parent attitude survey (PAS) of Drews and Teahen (1957), and 3) evaluation of students' creativity by masters. Statistical population of the study includes all students of Urmia Medical Sciences University (209 males and 218 females) and their parents. Data analysis was performed by SPSS software using descriptive and inferential statistical methods. Results indicate no significant relationship between student creativity and parents attitude on youth fostering $(r=0.20)$ and parents put more emphasis on educational success than creativity. Also, female students had better performance than males in terms of creativity.
\end{abstract}

\section{Keywords}

Youth-Fostering Styles, Parents' Youth-Fostering Attitude, Creativity, Dimensions

\footnotetext{
${ }^{*}$ Corresponding author.
}

How to cite this paper: Nejad, B.A., Jenaabadi, H., Ghafarshuja, N. and Heydaribisafar, H. (2015) Study of the Relationship between Parenting Attitude of Youth Fostering and Creativity among Students of Universities. Journal of Behavioral and Brain Science, 5, 148-156. http://dx.doi.org/10.4236/jbbs.2015.54015 


\section{of Creativity}

\section{Introduction}

Coming up with a novel thought, idea and concept is the basis for any invention, discovery and problem solving approaches in human life. Advanced and civilized communities have always asserted human potential on creative thought to bring about prosperity and well-being. Aristotle identifies creativity as the only factor that ensures human development. Edward De Bono (1970) claims in Lateral Thinking: Creativity Step by Step [1] that it is splendid when a new and efficient idea contributes to realize one's goals. In our competitive world where any nation seeks to achieve new technologies and sources of power, genius and creative people are great sources of intellectual capital. Torrence declares that the chance of cultivating potential creativity can be the matter of rise or demise of any nation. It is noteworthy that, innovation and creativity as human characteristics are not confined to childhood and sustain throughout one's life. In other words, creativity may remain latent for an unknown period, but can be revived any time [2]. As Hemmati puts it, man is naturally bestowed with creative though and performance [3]. Considering the importance of creativity and the essential role of parents in promoting creativity in youth, providing parents, masters and authorities with new approaches on promoting creativity in youth and adolescents is of dire importance [4]. The present study seeks to clarify the nature of creativity and interactive effects of parents and masters in dealing with students in order to suggest mechanisms to improve this relationship.

A great majority of influential material and spiritual accomplishments in human history, from building historical monuments and the invention of car to presenting scientific theories and creating literary works is a function of creative thought. Clearly, lack of creativity and innovation degrades our world into the simple and trite world of other living things like animals [5]. In fact, the gifted find and pave new ways to be followed by the public. Also, Kefayat (1994) introduces creativity as prior to knowledge and science [6]. However, creativity gains importance when we recognize that it explains a great part of innovations and achievements in science, industry, culture and civilization, and human welfare, without which life would have been a scene of immobility [7]. Therefore, dealing with such an issue directly corresponds to social life and the future of humanity.

Toffler (1980) [8] criticizes the absence of creativity in community as a result of ineffectiveness of the ministry of education which is responsible for balancing between stability and desired changes in society to inhibit any unwanted shocks to social structures in the future. Educational institutes should focus mainly on policies and plans that support intellectual and practical creativity of learners. Schools are not asked in any way to produce recording tapes, but they are strongly motivated to advance thought, creativity, and learning skills [9]. Therefore, creative thinking should be recognized as an important skill of compatibility that need to be embedded in school curriculum and properly introduced to parents, institutes and the industry [10]. Accordingly, any opportunity for creative thought is either cast out or denied. Even worse, creative performance of students may be suppressed by masters and parents and innovation may be interpreted as transgressing or lowering standards [11].

Gordon states that creativity can be fostered by a series of group exercises, while many teachers are unaware of beneficial applications of models that lead to innovative and creative thought. On the other hand, parents tend to direct their youth in ways they have experienced and elude any innovation in education.

Creativity is considered to be more influential on students, particularly in early ages, provided that masters and parents appear as supportive and encouraging. Thus, importance of the matter is stressed considering the following issues:

1) Creative thought reduces educational and administrative costs, and saves time.

2) New achievements and methods expire old ways of doing things and promote welfare of the society Creativity contributes greatly to cultural development of nations and breeds innovative individuals that are confident and feel honored and glorious.

3) Lack of innovative thought drives any community to imitation, consumption, dependence and inertia. Therefore, creativity helps sustain independence and productivity.

4) Communities are distinguished by their level of technological advances and novelty of ideas; so, developing countries need to adopt creative executive and educational policies. 
5) Creative people are more likely than others to achieve success and compatibility. They are quick to find solutions and rarely fail. They don't see success just in education and seek success in different aspects of life.

Considering the above measures, the study aims at inspecting the relationship between parenting attitude on youth fostering and student creativity. It also tries to identify educational methods and social value systems that encourage or discourage creativity [1].

\section{Creativity}

Like any other theoretical concepts, creativity is defined according to a specific school of thought that determineits nature, origin and functionality. A range of definitions has been given about creativity, such as divine gift, insanity, intuitive intelligence, and theories of associations, gestalt, psychoanalysis, factor analysis, and synecticsare presented in this regard. Brono [12] defines creative thinking as one which is characterized by abandoning unnecessary assumptions and making new thoughts. Guilford is possibly the most well-known thinker in regard to creativity. According to him, intelligence includes 120 factors and capacities, from which only 50 have been identified by now. These capacities are viewed as relating to memory or thought which is subdivided to convergent or divergent thinking. Guilford establishes eight dimensions for divergent thinking or creativity: sensitivity to problems, fluency, new ideas, flexibility, co-entity, analysis, complexity, evaluation. Guilford, however, noted that creative thinking is not the same as divergent thinking.

Inspired by Guilford's framework, Torrence [10] defined creativity as "a process of becoming sensitive to problems, deficiencies, gaps in knowledge, missing elements, disharmonies, and so on; identifying the difficulty; searching for solutions, making guesses, or formulating hypotheses about the deficiencies: testing and retesting these hypotheses and possibly modifying and retesting them; and finally communicating the results.” However, he introduced four important factors:

1) Fluency: refers to the production of a great number of ideas or alternate solutions to a problem.

2) Originality: involves the production of ideas that are unique or unusual.

3) Flexibility: refers to the production of ideas that show a variety of possibilities or realms of thought.

4) Elaboration: is the process of enhancing ideas by providing more detail.

In simple words, creativity is a mental ability to produce new ideas or concepts. It depends on the process of thinking and comprises finding new and efficient ways [13].

Personality traits of creative people: many theorists have determined personality traits of creative people. In mid-1980s, they are summarized in five factors in this regard:

a) Tendency to success: defines people who always seek to realize their goals.

b) Self-control: people whose life is determined by volition and control rather than chance.

c) Risk tolerance: people who are not afraid of taking risks.

d) Facing the ambiguous: denotes people who don't need all things clear to make decisions.

e) Type A behavior: refers to people who seek maximum results, even if they are opposed.

School and creativity: in the past, as some philosophers like Aristotle asserted, education was considered to transform limited "being" to limitless "becoming" or to create the need for learning not presenting knowledge [14]. In the modern times, schools are in charge of promoting creativity through pre-determined plans and policies designed in the ministry of education. Torrence observed in his studies that development of knowledge (increasing information through memorization) is accompanied by limited judgment and imagination. According to Ribute, that imagination grows faster than reasoning. Therefore, as children grow older, their creativity is slaughtered by reasoning, logic and habits and, in practice, acquisition of knowledge and experience turn to chain students' imaginative minds [15].

Moreover, masters-based educational systems is considered to be an ineffective way of teaching since it lays more emphasis on consuming rather than producing knowledge [16]. Ivan Ilich interestingly says that education shuts down when school doors open. No doubt, new and creative systems should continuously replace old ones to revise content, attitude and approaches based on individual skills growth of children.

Sirotnick and Clark [17] acknowledge particular role of schools on promoting creativity and assert that final opportunity for any modifications in education is in the hand of those who work at school. In fact, education is productive when it is designed according to demands of teachers and students, encourages students and teachers to reveal their thoughts and emotions and carefully observes students' problems [18]. Some teaching techniques for encouraging creativity are as follows: promoting imagination, motivation, establishing freedom, building 
proper structures, establishing a suggestions system, accepting the principle of individual differences, making flexible environments, observing creative patterns of behavior, activating brainstorming, applying indirect imagination and thinking, parallel thinking, applying Delphi methodology, use of humor, and employing six thinking hats technique as follows: white hat (reality and information), red hat (emotion and feelings), black hat (critical judgment), yellow hat (positive judgment), green hat (learning and alternatives), and blue hat (big picture).

\section{Creativity and Youth-Fostering}

Creativity of youth depends on environmental factors, particularly parenting attitude on fostering youth. Here, attitude implies conscious and relatively fixed beliefs and desires about things. The present study assumes that the way parents treat their youth stems from their attitudes. There is evidence that family is highly influential on controlling and guiding imagination and creativity in children and youth. Studies show that creative and uncreative family atmosphere is an effect of the interaction of parents and youth [19]. In early $20^{\text {th }}$ century, behaviorist ideology dominated and determined educational methods and behavioral patterns of parents. Nevertheless, following advocates of psychoanalysis in 1940s, particularly Spock, that stressed on the importance of emotion, satisfying needs and disadvantages of extreme control of natural desires, parents turned to be more permissive and flexible [6]. Parents generally use one of the techniques of domination, high dependency, and negligence to bring up their children. Domination is excess control on children's behavior and speech. High dependency is the situation where parents devote themselves to their youthand support them even in adulthood. On the contrary, permissive and negligent parents exert no control over their youth and expect nothing [20]. Baumrind [9] found in his studies that raising children is a two-fold process. On the one hand, some parents set high criteria for their youth and expect them to realize these criteria. On the other hand, some parents are more accountable and respond to their children and seem to engage in discussion with them. Finally, the others pay no attention to their children. However, four parenting styles are briefly described here as follows.

1) Authoritative: is considered to be the best way of dealing with children. Authoritative parents have reasonable expectations and set restrains to make their children follow their rules. However, they keep a friendly and kind relationship with them, listen patiently to them, and encourage them to take part in family decisions. Authoritative child fostering is a logical and democratic style that preserves rights of parents and youth. Baumrin demonstrated that this parenting style delivers successful children who are happy, confident, self-sufficient and tend to be less sexually oriented. Boys score higher in terms of friend and supportive behavior and girls show independent and acquiring new skills [21].

2) Arbitrary: these parents are demanding and put too much stress on obedience, such that children feel disinclined to follow what they require. Since they expect full submission of children, no communication occurs between them and any disobedience meets more force and punishment. Children are usually angry, rebellious, dependent, uncurious, and avoid challenging tasks.

3) Permissive: permissive parents are kind and receptive, but not expectant and exercise no control measures. They allow their children to decide for themselves, even if they are not prepared for that. Baumrind reported that these children are premature, highly expectant and dependent on adults.

4) Unmediated: is characterized by unexpectedness and non-interference. Parents who have no role in their children's life are mostly depressed and overstressed. They have no energy or time for their children. In its radical form, unmediated parenting is a sort of youth abuse and, if practiced in early childhood, disturbs any idea of recognition, emotional and social emotion and the sense of attachment [22].

Studies show that creative youth come from families with less dominative attributes, in which they are brought up in an atmosphere of freedom and compatibility.

\section{Review of Literature}

To our knowledge, no study has been conducted by far to deal with the above-mentioned variables. Parnes [23], De Bono [1] found that all people possess creativity in different degrees. Hartly [24] demonstrated that free educational atmosphere and plurality of responses instead of single response, enhances creativity and self-depended in children. Ezazi [22] studied effects of others on individual creativity and reported that creative people are independent and are not impressed by others. Parents of smart students are usually obsessed with educational success, observing order and politeness, while parents of creative children are mostly concerned about values and confronting problems of life. They also tend to be less preoccupied with risks and discuss about financial mat- 
ters [22].

Kefayat [6] found a significant and positive correlation between parental styles and creativity. However, creativity seems to be more related to intelligence and educational success. Feraghat [25] reported a direct and significant relationship between creativity and conductive educational atmosphere. Hassanzadeh [26] concluded in his study that brainstorming at school positively affects creativity and is convenient to apply. Bayrami et al. [27], found that permissive and arbitrary styles of parenting are more common in addict parents, while normal parents tend to be more inclined to be authoritative. Jalali et al. [28] revealed in their study that mothers recourse frequently to permissive and arbitrary styles. Rezaei \& Khodakhah [21] reported no significant relationship between parental styles and educational success. Results of Golafzani et al. [29] indicate that parental styles differ for mothers with depressed, anxious, and obsessed children, compared to mothers with normal children. The authors realized that the former tend to be more inclined to use arbitrary style, while the latter are decisive and reassuring.

\section{Methodology}

The present study is a descriptive and correlative analysis of parenting attitudes, as independent variables, and creative ideas, imagination, emotion and feelings and performance as dependent variables.

Population size of the study includes a total number of 427 male (209) and female (218) students of Urmia Medical Sciences University and their parents (427). Also, 76 masters in direct relationship with students were selected. A census methodology was used for sampling. A total number of 418 questionnaires were distributed and 363 were collected.

\subsection{Research Tools}

The study used three questionnaires as 1) multiple choice paper and pencil test for measuring Torrance creativity (1971), 2) parent attitude survey (PAS) of Drews and Teahen (1957), and 3) evaluation of students' creativity by masters. Creative thinking test of Torrence is used here that measures four factors on creativity: fluency, originality, flexibility and elaboration. Parent attitude survey, proposed by Shoben (1949), is used as designed by Drews and Teahen (1957) which contains 30 questions of five choices analyzing domination, high dependency, and negligence. Finally, evaluation of students' creativity by teachers is conducted as an external and control factor to calculate its correlation with creativity. First, creativity and its components were explained to masters and, then, they were asked to evaluate students in a 5-scale measure.

\subsection{Reliability and Validity}

A content analysis method was used to measure validity of questionnaires based on Torrence creativity factors, which were determined to be as follows: fluency: 0.09; flexibility: 0.011 ; originality: 0.013 ; and elaboration: 0.27 . Kefayat [6] found in his study that overall validity of the test is 0.27 , fluency 0.09 , flexibility 0.13 , originality 0.015 and elaboration 0.24 and coefficient of correlation at 0.05 was significant. Abedi [30] reported a significant correlation between the four factors of Torrence creativity test and Abedi creativity test.

Validity of PAS questionnaire evaluated by Kefayat at 0.001 was significant and found for the three factors of domination, high dependency, and negligence to be $0.35,0.29$, and 0.46 , respectively. However, values obtained by the author were $0.39,0.30$, and 0.49 for domination, high dependency, and negligence, respectively.

Reliability of creativity test by the author was 0.82 and using Chronbachalpha for fluency, flexibility, originality, and elaboration was found to be $0.74,0.79,0.83,0.76$ and 0.74 , respectively. These results are significant when $\mathrm{P}<0.05$. Abedi reported reliability of creativity test between 0.80 and 0.90 and for fluency, originality, flexibility and elaboration were $0.85,0.82,0.85$ and 0.80 , respectively. Results by using Chronbach alpha were significant at $\mathrm{P}<0.05$ and for total creativity, fluency, flexibility, originality, and elaboration were found to be $0.78,0.78,0.81,0.73$ and 0.70 , respectively.

Reliability of results of PAS questionnaire by Kefayatfor total creativity, domination, high dependency, and negligence using Spearman-Brown were $0.22,0.20,0.16,0.11$ and 0.11 , respectively. These results were significant at 0.05 , except for domination and negligence. Results obtained by the author for total creativity, domination, high dependency, and negligence were $0.25,0.28,0.14,0.18$ and 0.19 , respectively. 


\subsection{Statistics}

Data analysis was performed using SPSS and descriptive statistics (classification criteria, variance dispersion measures, standard deviation, and frequency table). Hypotheses were tested using parametric inferential methods (correlation test, t-test and analysis of variance).

\section{Findings}

In this section, descriptive and inferential methods are used for explaining collected data. Table 1 and Table 2 demonstrate distribution of parenting attitudes and distribution of Torrence creativity.

Table 1 implies that $92.5 \%$ of parents have an average attitude towards child fostering, and $7.5 \%$ have high attitudes on this issue.

As demonstrated in Table 2, level of creativity among students ranges from $17.5 \%$ very low, $28.7 \%$ low, $42.4 \%$ high and $11.6 \%$ very high.

\section{Testing Hypotheses}

$\mathrm{H}_{1}$ : there is a relationship between parenting attitudes and student creativity.

A Pearson correlation test was used for studying the relationship between parenting attitudes andTorrence creativity. Table 3 shows that level of parenting attitudes is linearly correlated with fluency $(r=0.174, P=$ $0.003<0.005)$, elaboration $(r=0.161, P<0.005)$ and originality $(r=0.143, P<0.005)$. Nevertheless, no significant relationship was observed for parenting attitudes and flexibility $(\mathrm{P}>0.005)$. Also, parenting attitudes had a significantly low correlation with creativity $(\mathrm{r}=0.20)$.

$\mathrm{H}_{2}$ : parenting attitudes lead to different levels of creativity among male and female students

Level of creativity among female and male students was measured using t-test of independent groups. Results indicate that level of creativity foe male and female students was found to be $33.61 \pm 5.06$ and $32.18 \pm 5.80$, respectively. Therefore, it can be said that t-test is error level of 0.05 is significant. That is to say, fluency among female students is stronger than males $(\mathrm{P}<0.05)$. Elaboration for female and males students was significant at error level of $0.05(\mathrm{P}<0.05)$ and found to be $15.54 \pm 3.17$ and $13.88 \pm 3.27$, respectively. In other words, elaboration among female students is stronger than males. Also, originality at error level of $5 \%(\mathrm{P}=0.011<$

Table 1. Distribution of parent attitudes.

\begin{tabular}{ccc}
\hline Attitude & Frequency & Percent \\
\hline Average & 248 & $92.5 \%$ \\
High & 20 & $7.5 \%$ \\
Total & 268 & $100 \%$ \\
\hline
\end{tabular}

Table 2. Distribution and relative abundance of Torrnece creativity.

\begin{tabular}{ccc}
\hline Attitude & Frequency & Percent \\
Very low & 47 & $17.5 \%$ \\
Low & 77 & $28.7 \%$ \\
High & 113 & $42.2 \%$ \\
Very high & 31 & $11.6 \%$ \\
\hline
\end{tabular}

Table 3. Parenting attitude and creativity.

\begin{tabular}{lcccccc}
\multicolumn{2}{c}{ Creativity } & Fluency & Elaboration & Originality & Flexibility & Creativity \\
\hline & Correlation & 0.174 & 0.161 & 0.143 & 0.20 \\
Parenting attitude & P-value & 0.003 & 0.005 & 0.013 & 0.001 \\
\hline
\end{tabular}


0.05) was significant and was found to be $23.20 \pm 4.32$ and $21.87 \pm 5.12$ for female and male students, respectively. Namely, originality among female students is stronger than males. In addition, flexibility was significant and was found to be $17.25 \pm 2.471$ and $16.11 \pm 3.01$ for females and male students, respectively. In other words, female students have better performance in terms of elaboration. Finally, results of Torrence creativity revealed that female students are relatively more creative than male ones $(\mathrm{P}=0.002<0.05)$ (Table 4).

$\mathrm{H}_{3}$ : The relationship between parenting attitudes and creativity is not congruent

As can be seen in Table 5, level of parenting attitudes was confined to average and high which impels the use of t-test. Results indicated that level of creativity for parents with average and high attitudes is $32.93 \pm 5.60$ and $33.04 \pm 4.71$, respectively, which are not significant at error level of 0.05 . in simple words, fluency doesn’t change with parenting attitudes. The same holds true for the relationship between parenting attitudes with elaboration, originality and flexibility $(\mathrm{P}<0.05)$.

$\mathrm{H}_{4}$ : there is a relationship between parenting attitude and creativity

As can be seen in Table 6, a correlation test was used for evaluating the relationship between parenting attitudes and creativity. Our results indicate that domination and high dependency have a relatively low correlation with creativity.

\section{Conclusions}

Creativity and innovation are essential components of our modern complex societies that ensure dynamism in human life. Accordingly, policy-makers, leaders, families and authorities that are responsible for educating people are obliged to find and implement ways to cherish creativity. However, identifying and fostering creativity among gifted students in exceptional talents is considerably important. The present study instigated the relationship between creativity and parenting styles. Results obtained in the study are as follows:

Table 4. Levels of creativity among male and female students.

\begin{tabular}{cccccc}
\hline Variable & Sex & Mean & Standard deviation & t-statistics & P-value \\
\hline \multirow{2}{*}{ Fluency } & Female & 33.61 & 5.06 & 2.43 & 0.015 \\
& Male & 32.18 & 5.80 & 3.35 & 0.001 \\
Elaboration & Female & 15.54 & 3.17 & 3.27 & 0.011 \\
Originality & Male & 13.88 & 4.32 & & 0.00 \\
Flexibility & Female & 23.20 & 5.12 & 3.88 & 0.00 \\
Male & Female & 21.87 & 2.47 & 3.07 & 0.09 \\
\hline
\end{tabular}

Table 5. Creativity and parenting attitudes.

\begin{tabular}{|c|c|c|c|c|c|c|}
\hline \multicolumn{2}{|c|}{ Parenting attitudes } & \multirow{2}{*}{\begin{tabular}{c|} 
Mean \\
32.9307 \\
33.0435
\end{tabular}} & \multirow{2}{*}{$\begin{array}{c}\begin{array}{c}\text { Standard } \\
\text { deviation }\end{array} \\
4.60275 \\
4.71437\end{array}$} & \multirow{2}{*}{$\begin{array}{c}\begin{array}{c}\text { Standard } \\
\text { deviation error }\end{array} \\
0.33847 \\
0.98301\end{array}$} & \multirow{2}{*}{$\begin{array}{c}\text { t-statistics } \\
-0.09\end{array}$} & \multirow{2}{*}{$\begin{array}{r}\text { P-value } \\
0.92\end{array}$} \\
\hline Fluency & $\begin{array}{c}\text { Average attitudes } \\
\text { High attitudes }\end{array}$ & & & & & \\
\hline Elaboration & $\begin{array}{c}\text { Average attitudes } \\
\text { High attitudes }\end{array}$ & $\begin{array}{l}14.50540 \\
13.41167\end{array}$ & $\begin{array}{l}3.23771 \\
3.17486\end{array}$ & $\begin{array}{l}0.19454 \\
0.64806\end{array}$ & 1.58 & 0.115 \\
\hline Originality & $\begin{array}{c}\text { Average attitudes } \\
\text { High attitudes }\end{array}$ & $\begin{array}{l}22.3556 \\
21.5652\end{array}$ & $\begin{array}{c}4.864661 \\
4.08797\end{array}$ & $\begin{array}{l}0.29605 \\
0.85240\end{array}$ & 0.75 & 0.95 \\
\hline Flexibility & $\begin{array}{c}\text { Average attitudes } \\
\text { High attitudes }\end{array}$ & $\begin{array}{l}16.7845 \\
17.1364\end{array}$ & $\begin{array}{l}2.79301 \\
2.60577\end{array}$ & $\begin{array}{l}0.16603 \\
0.55555\end{array}$ & -0.57 & 0.58 \\
\hline Torrence creativity & $\begin{array}{c}\text { Average attitudes } \\
\text { High attitudes }\end{array}$ & $\begin{array}{l}86.2984 \\
84.8000\end{array}$ & $\begin{array}{l}13.52669 \\
12.63496\end{array}$ & $\begin{array}{l}0.89856 \\
28.2526\end{array}$ & 0.47 & 0.63 \\
\hline
\end{tabular}


Table 6. Level of correlation for parenting attitudes and creativity.

\begin{tabular}{ccccccc}
\hline \multicolumn{2}{c}{ Attitude/creativity } & Fluency & Elaboration & Originality & Flexibility & Creativity \\
\hline \multirow{2}{*}{ domination } & Correlation & 0.128 & 0.166 & 0.117 & 0.086 & 0.160 \\
& P-value & 0.022 & 0.003 & 0.039 & 0.11 & 0.007 \\
\multirow{2}{*}{ High dependency } & Correlation & 0.113 & 0.074 & 0.096 & 0.111 & 0.145 \\
& P-value & 0.013 & 0.180 & 0.098 & 0.042 & 0.013 \\
Negligence & Correlation & 0.109 & 0.108 & 0.093 & 0.022 & 0.119 \\
& P-value & 0.062 & 0.60 & 0.111 & 0.71 & 0.052 \\
\hline
\end{tabular}

Parenting attitude has a relatively low influence on creativity of students $(r=0.20)$. It implies that parents have no clear perspectives to support creativity in their children and tend to be more conservative in this regard. This explains the priority of educational success over creativity among youth and parents. However, there may be some other factors in place, like behavioral attitudes of parents. Parents lay greater stress on educational success than creativity. These findings are in agreement with results of Mandara (2006) and Mc Kinon (1991), though being in disagreement with Kefayat (1994).

Results indicate that creativity (originality, flexibility, elaboration) is stronger in female students as compared to males. Prematurity, along with physical-mental differences among girls and boys, may explain this supremacy. Parenting attitude has no effects on creativity. Parents seem to be uncertain about creativity and negligence found to have no relationship with creativity $(\mathrm{P}<0.05)$. However, originality and flexibility found to have no statistical relationship with high dependency and domination, respectively.

\section{Limitations of the Study}

The study underwent some limitations while investigating creativity and its relationship with parenting attitudes, such as tendency to choose the best choice, non-participation of masters, minor role of creativity in school curriculum, and parents' nonconformity with this plan. Also, long and complex nature of questionnaires contributed to imprecise answers and fatigue. Lack of sampling and generalization were also influential.

\section{Practical Suggestions}

Considering negligible effects of parenting attitudes on creativity, the study proposes the following practical suggestions:

- Inductingyouth-fostering styles that support creativity.

- Taking note ofmasters' comments and suggestions and encouraging active participation.

- Planning to foster creativity instead of mere educational success.

- Planning to change parenting attitudes to promote creativity.

- Revising contents of educational material and teaching methodologies to support creativity.

- Holding short-term courses on activating student participation for masters.

- Building research and development centers in education ministry that foster creativity.

- Celebrating annually the local achievements of creative students.

- Improving job satisfaction, self-esteem, and social prestige of masters.

- Building dynamic and flexible structure in educational institutes.

- Appointing school principals who are familiar with creative teaching methodologies.

- Delegating educational issues to promote participation and foster creativity.

\section{Suggestions for Further Studies}

- Comparative analysis of educational systems in terms of creativity.

- Comparative analysis of creativity in typical and exceptional talents schools.

- Studying creativity on a large population.

- Studying cultural-social factors on creativity.

- Studying inhibitive cultural-social factors on creativity. 


\section{References}

[1] De Bono, E. (1970) Lateral Thinking: Creativity Step by Step. Harper \& Row, New York.

[2] Torrence, E.P. (1971) Technical Norms Manual for the Creative Motivation Scale. Georgia Studies of Creative Behavior, University of Georgia, Athence.

[3] Hemmati, A. (2009) Comparative Analysis of Obstacles on Creativity in Students in Urmia. M.A. Thesis.

[4] Cropley, A.J. (1992) More Ways than One: Fostering Creativity. Ablex, Norwood.

[5] Simonton, D.K. (2000) Creativity: Cognitive, Developmental, Personal and Social Aspects. American Psychologist, 55, 151-158. http://dx.doi.org/10.1037/0003-066X.55.1.151

[6] Kefayat, M. (1994) Evaluating the Relationship between Parenting Styles and Creativity in Ahwaz. M.A. Thesis.

[7] Amabile, T.M. (1983) The Social Psychology of Creativity. Springer, New York. http://dx.doi.org/10.1007/978-1-4612-5533-8

[8] Toffler, E. (1980) Future Shock. Golshan Publishing, Tehran.

[9] Khomarlou, T. (1991) Kids’ Trainer. Agah Publishing, Tehran.

[10] Torrance, E.P. and Safter, H.T. (1986) The Long Range Predictive Validity of the Just Suppose Test. Journal of Creative Behavior, 23, 219-223. http://dx.doi.org/10.1002/j.2162-6057.1989.tb00696.x

[11] Smith, G.J.W. and Carlsson, L.M. (1990) The Creative Process: A Functional Model Based on Empirical Studies from Childhood to Middle Age. International Universities Press Inc., Madison.

[12] Brono, F. (1991) Descriptive Psychology. Translated by Yasaei, M.T., No Publishing.

[13] Parker, S.K., Wall, T.D. and Jackson, P.R. (1997) That’s Not My Job: Developing Flexible Employee Work Orientations. Academy of Management Journal, 40, 899-929. http://dx.doi.org/10.2307/256952

[14] Qasemi, A. (2005) Effects of Traditional and Modern Teaching Methodologies on Creativity. Sepehr Publishing, Tehran.

[15] Seif, S. (1993) Family Growth Theory. Alzahra University Publishing, Tehran.

[16] Faqihi, N., Parand, A. and Shokouhi, M. (2005) A Comparative Analysis of Parenting Styles and Creativity. Journal of Hozeh and Daneshgah, Islamic Education, 2, 115-140.

[17] Sirotnik, K.A. and Clark, R.W. (1988) School-Centered Decision Making and Renewal. Phi Delta Kappan, 52, 660664.

[18] Sjostrom, E. (1967) Psychology of Dominant People. Sepehr Publishing, Tehran.

[19] Baumrind, D. (1967) Child Care Practices Anteceding Three Patterns of Preschool Behavior. Genetic Psychology Monographs, 75, 43-88.

[20] Yousefi, B. (2004) Innovation in Ministry of Education. Journal of Management in Ministry of Education, 14, 1-12.

[21] Rezaei, A. and Khodakhah, S. (2009) The Relationship between Child-Fostering and Beliefs with Achievement between High School Students. Journal of University of Yazd, 5, 117-134.

[22] Ezazi, S. (1997) Sociology of Family Structure in Contemporary Life. Roshangaran Publishing, Tehran.

[23] Parnes, S.J. (1967) Creative Behavior Guidebook. Scribners, New York.

[24] Hartly, E. (1988) Motivating Children. Javaneh Roshd Publishing, Tehran.

[25] Feraghat, L. (2002) Study Relationship of School Environment and Creativity in Tehran High School. Culture and Research, 167, 23.

[26] Hassanzadeh, F. (2004) Effects of Brainstorming on Creativity. Agah Publishing, Tehran.

[27] Bayrami, M., Mohammadpour, V., Qolamzadeh, M. and Esmaeili, B. (2008) A Comparative Evaluation of Parenting Styles and Patterns of Relationship in Normal and Addicted Families. New Control of Addiction, Part of Research and Articles in Battle of Narcotic Office, 1, 1-18.

[28] Jalali, M., Pourahmadi, E., Shoeiri, M. and Tahmasbian, K. (2009) Effects of Positive Child-Fostering Plans on Parenting Styles in Children with Disobedience Disorder, Research Report.

[29] Golafzani, M., Moahmmadesmaeil, E. and Raoufian, F. (2003) Parenting Styles in Depressed, Obsessed, Anxious and Normal Children. Journal of Exceptional Children, 10, 245-264.

[30] Abedi, J. (2002) A Latent-Variable Modeling Approach to Assessing Reliability and Validity of a Creativity Instrument. Creativity Research Journal, 14, 267-276. http://dx.doi.org/10.1207/S15326934CRJ1402_12 